\title{
Инновационный потенциал региональной экономической системы: условия формирования и факторы развития
}

Большинство индустриально развитых стран связывает свои надежды на долгосрочный устойчивый экономический рост с переходом на инновационный путь развития, характеризующийся более широким использованием в промышленности, народном хозяйстве в целом новейших достижений науки и техники - информационных технологий, биотехнологий, новых материалов, ресурсо- и природосберегающих технологий. Инновационное развитие обеспечивает высокую добавленную стоимость продукции. Переходя на инновационное развитие, экономика становится менее зависимой от ценовой конъюнктуры и более устойчивой к разного рода кризисным явлениям. В этом аспекте переход на инновационное развитие весьма желателен для экономики России.

Инновационность региона - это его способность к самообновлению, адаптации к изменениям и генерированию продуктов научно-технического прогресса. Мировой опыт показывает, что устойчивое развитие производства и поддержание его конкурентоспособности в долгосрочной перспективе зависит не столько от ресурсных возможностей, сколько от инноваций.

В настоящее время российская экономика находится на этапе разработки и реализации стратегии инновационного развития, которая характеризуется способностью обеспечения будущего страны и постепенным отказом от политики «крупных форм» и масштабных решений. В связи с этим, необходима интеграция мер общегосударственного плана (реорганизация и дополнительная поддержка отечественной науки, налоговые льготы субъектам инновационной деятельности и инвесторам и пр.) с последовательным формированием отдельных «точек» инновационного развития и обновления экономики регионов. Политика инновационного развития экономики должна основываться на новом качестве управления с учетом согласования усилий федерального, регионального и местного звеньев управления.

Различие условий экономического развития и жизнедеятельности в регионах является одной из важнейших характеристик российской экономики, что способствует поиску общих тенденций развития регионов и индивидуальных вариантов сценарных прогнозов экономического роста. Особенности природно-ресурсного потенциала, геополитического положения, структуры хозяйственных комплексов различных видов деятельности предопределили многократный разрыв уровней по важнейшим показателям социально-экономического развития субъектов Федерации, глубину кризисных явлений, 
различную реакцию на экономические трансформации и темпы выхода на экономический рост. В настоящее время понятие инновационного потенциала широко применяется в экономической теории и практике, а так же привело к ряду самостоятельных исследований, посвященных анализу различных подходов к оценке этой экономической категории, при этом вопросы развития и управления инновационным потенциалом различных экономических систем в отечественной литературе трактуются весьма неоднозначно. Обобщая исследования, можно выделить несколько наиболее ключевых подходов к трактовке данного определения:

- совокупность различных видов ресурсов, необходимых для осуществления инновационной деятельности;

- способность системы к трансформации в новое состояние с целью удовлетворения потребностей (индивида, рынка и т. п.);

- структура, объединяющая три составляющие потенциала: ресурсную, внутреннюю и результативную, которые существуют во взаимодействии, предполагают и обусловливают друг друга;

- возможность создания новшеств, осуществления инноваций, готовность воспринять нововведения для последующего эффективного использования на уровне, соответствующем мировому [3].

Сущность любого объекта достаточно полно раскрывается посредством выявления его структуры. Структура инновационного потенциала может быть представлена единством трех его составляющих: ресурсной, внутренней и результативной, которые сосуществуют взаимно, предполагают и обуславливают друг друга.

Ресурсная составляющая инновационного потенциала является своего рода основой для его формирования. Она включает в себя следующие основные компоненты, имеющие различное функциональное назначение: материально-технические, информационные, финансовые, человеческие и другие виды ресурсов. Так, материально-технические ресурсы, являясь «вещественной основой, определяют технико-технологическую базу потенциала, которая впоследствии будет влиять на масштабы и темпы инновационной деятельности» [2]. В свою очередь сами они формируются в отраслях, изготавливающих средства производства, которые путем применения новых технологий закладывают в них потенциальные возможности, реализуемые или нереализуемые впоследствии.

Следующая компонента ресурсной составляющей - информационный ресурс (такие еe активные формы, как базы знаний, модели, алгоритмы, программы, проекты и т.д.) подобно катализатору переводит материальные факторы из скрытого состояния в активное. Данный вид ресурсов, в отличие от прочих, практически неисчерпаем. 
C развитием общества и активизацией использования знаний запасы информационного ресурса не уменьшаются, а напротив, увеличиваются. При этом этот вид ресурсов не самостоятелен и сам по себе имеет лишь потенциальное значение, только объединившись с другими ресурсами - опытом, трудом, квалификацией, техникой, технологией, энергией, сырьем, он появляется в «кинетике» как движущая сила инновационного потенциала.

Финансовые ресурсы входят в состав ресурсной составляющей инновационного потенциала как органическое единство наличных ресурсов и неиспользованных возможностей их альтернативного вложения. Таким образом, они характеризуются совокупностью источников и запасов финансовых возможностей, которые есть в наличии и могут быть использованы для реализации конкретных целей и заданий. При этом объем финансовых ресурсов отображает финансовую мощь, способность системы принимать участие в создании материальных благ и предоставлении услуг. Однако, помимо обеспечивающей функции, финансовые ресурсы выполняют и страховую функцию, непосредственным образом дублируя, а также измеряя в денежных единицах материальнотехнические, информационные, человеческие и другие ресурсы, входящие в состав инновационного потенциала.

Таким образом, значение этого ресурса неоднозначно. С одной стороны, в силу своей ограниченности он вынуждает искать более экономичный вариант, исходить из того, что есть, интенсифицировать использование имеющихся факторов, т.е. приводит в движение всю систему. С другой - его лимитированный характер может затормозить или погасить формирование и реализацию самого инновационного потенциала. Тем не менее, одно остается несомненным - этот вид ресурсов непосредственным образом (качественно и количественно) влияет на инновационный потенциал.

Следующей компонентой ресурсной составляющей инновационного потенциала является человеческий ресурс, который не просто выполняет обеспечивающую функцию (как все предыдущие), а выступает главной движущей силой. Это совокупность проинвестированных общественно целесообразных производственных и общечеловеческих навыков, знаний, способностей, которыми владеет человек, которые ему принадлежат, неотделимы от него, и практически используются в повседневной жизни. Немаловажным является то, что указанная компонента оказывает непосредственное влияние не только на ресурсную составляющую инновационного потенциала, но и на внутреннюю и особенно результативную.

Второй составляющей инновационного потенциала является внутренняя составляющая - так называемый «рычаг», обеспечивающий дееспособность и эффективность 
функционирования всех предыдущих элементов. В целом, указанная составляющая характеризует возможность целенаправленного осуществления инновационной деятельности, т.е. определяет способность системы на принципах коммерческой результативности привлекать ресурсы для инициирования, создания и распространения различного рода новшеств. Таким образом, внутреннюю составляющую можно охарактеризовать через процессы создания и внедрения нового продукта, обеспечения взаимосвязи новатора как с наукой, предоставляющей прогрессивные идеи, так и рынком, потребляющим готовый продукт, а также методы и способы управления инновационным процессом. Указанная составляющая является довольно сложной и важной, и поэтому для детального еe анализа отдельные авторы предлагают использовать структурноинституциональный и функциональный подходы. При этом структурно-институциональный подход вычленяет структуру инновационной деятельности с точки зрения системы институциональных субъектов, ее осуществляющих, а также экономические связи с внешними для нее сферами - наукой и производством. Функциональный подход выявляет временные закономерности инновационного процесса - производство инновационного продукта, его обмен, распределение, потребление и возобновление цикла инновационного процесса, за которое и отвечает внутренняя составляющая инновационного потенциала.

Третьей составляющей инновационного потенциала является результативная составляющая, которая выступает отражением конечного результата реализации имеющихся возможностей (в виде нового продукта, полученного в ходе осуществления инновационного процесса). Таким образом, она - своего рода целевая характеристика инновационного потенциала. Важность этой составляющей и целесообразность обособленного выделения подтверждается тем, что ее увеличение, в свою очередь, способствует развитию остальных составляющих (например, ресурсной). Другими словами, результативная составляющая, сама являясь результатом количественного и качественного изменения, несет в себе потенциальные возможности вывода на новый уровень функционирования как инновационного потенциала, так и системы в целом.

Тесная взаимосвязь ресурсной, внутренней и результативной составляющих инновационного потенциала определяют необходимость выявления на практике их оптимального соотношения (исходя из роли и значимости, которую они играют в формировании и развитии потенциала). Так, например, незначительный удельный вес ресурсной составляющей, как правило, обусловлен превалированием качественных изменений над количественными. При этом ограниченность необходимых ресурсов временем и пространством может быть полностью или частично преодолена интенсификацией их использования, применением новых методов организации процесса, 
поиском новых источников их привлечения. При этом, очевидно, существует определенный предел отклонения величины составляющих инновационного потенциала от оптимального уровня. То есть дальнейшее изменение какого-либо элемента влечет за собой либо снижение отдачи от него самого, либо уменьшение эффективности функционирования остальных элементов, так как все они существуют в системном единстве [4].

Таким образом, вопрос формирования инновационного потенциала является важным, и ввиду своей сложности требует эффективного управления.

Непременным условием инновационного развития является правовое обеспечение, предполагающее, прежде всего, адаптацию к правовой базе формирующейся инновационной системы РФ и создание соответствующих нормативно-правовых документов, обеспечивающих полноценное и эффективное функционирование инновационной деятельности в регионе [1]. В настоящее время действует довольно большое число нормативно-правовых актов, регулирующих отдельные стороны процесса создания научнотехнических разработок и их реализации, но их положения зачастую оказываются не соответствующими новым условиям научно-технического и инновационного развития. В условиях формирования рыночной экономики в России сохраняется приоритетность прямых методов государственного регулирования инновационной деятельности. Неразвитость рынка инноваций вынуждает государство оставаться главным спонсором и координатором размещения заказов на выполнение научно-технических разработок и инновационных проектов. Но при ограниченных финансовых возможностях государства прямое финансирование инновационных проектов оказывается малоэффективным. Косвенные методы регулирования инновационной деятельности связаны с созданием благоприятных условий для предпринимательства в инновационной сфере. Они могут быть серьезным стимулом для привлечения частных инвестиций в сферу инноваций. Наиболее важным и распространенным методом косвенного регулирования является предоставление специальных налоговых льгот, стимулирующих инновационную деятельность. Однако стимулирующая функция налоговой системы применительно к инновационной деятельности в отечественной экономике практически не задействована.

На начальных этапах формирования инновационной системы региона представляется необходимым создать региональные структуры, цель деятельности которых максимально использовать возможности привлечения значительных федеральных ресурсов, а также ресурсов сырьевых компаний.

Инновационное развитие региона требует выполнения, по крайней мере, двух инновационных условий: передачи полномочий от национального к региональному (местному) уровням управления и осуществления задач содействия и стимулирования 
развития государственных, общественных и частных организаций в регионе [5].

Применение отдельных мер, направленных на улучшение процесса привлечения инвестиций в регионе, не дает должных результатов [6]. Необходим системный управленческий подход к решению проблемы на базе выработки и реализации государственной инвестиционной политики, направленной на восстановление процессов расширенного воспроизводства и ориентацию регионов на экономическую самодостаточность. Стратегической целью государственной инвестиционной политики в современных условиях должно быть формирование механизма инновационноинвестиционной деятельности через создание, к примеру, региональных инвестиционных фондов, адекватных формирующейся рыночной среде и вписывающихся в формирующиеся и развивающиеся рыночные институты.

Особая роль в структуре организационно-экономического механизма управления принадлежит региональным и муниципальным органам управления, поскольку от их компетенции зависит не только эффективность разрабатываемой и реализуемой инновационно-инвестиционной политики, но и вектор направленности социальноэкономического региона в целом. Инновационная деятельность традиционно связана с высоким уровнем риска: по статистике, только $10 \%$ всех внедряемых разработок имеет коммерческий успех. Поэтому, в первую очередь на уровне региональных и муниципальных властей необходимо создать и поддерживать систему управления коммерциализацией продуктов НИОКР, ориентированную на работу в рыночных условиях.

Региональные и муниципальные органы власти, которые в связи с близостью к субъектам хозяйствования, расположенным на соответствующей территории, способны наиболее эффективно управлять, проводить текущий мониторинг, контролировать их деятельность и оценивать их вклад в социально-экономическое развитие региона. Наряду с прямым финансированием и налоговыми методами стимулирования инновационной деятельности в регионах применяются и другие формы поддержки субъектов инновационной деятельности:

- создание условий для развития инновационной деятельности;

- ресурсное обеспечение инновационно-технологического развития;

- содействие продвижению продукции высокотехнологичных отраслей промышленности;

- взаимодействие исполнительных органов государственной власти субъекта РФ с организациями при формировании инновационной и промышленной политики;

- информационная поддержка инновационно-технологического развития.

Региональная инновационная политика реализуется в виде мер региональной 
поддержки, формирования благоприятного инновационного климата, повышения инновационной активности и инновационной восприимчивости регионов. В современных условиях задачей первостепенной важности является сохранение и последующее усиление инновационно-промышленного потенциала региона, повышение степени его воздействия на экономическую эффективность производства. Без этого недостижимо обеспечение устойчивости регионального развития.

На микроуровне инновационная деятельность осуществляется через соответствующие инновационные проекты. Инновационный проект представляет собой сложную систему взаимообусловленных и взаимосвязанных по ресурсам, срокам и исполнителям мероприятий, направленных на достижение конкретных целей на приоритетных направлениях науки и техники. Применение методологии проектного управления является наиболее эффективным подходом к оптимизации процессов реализации инновационных проектов. Она позволяет повысить эффективность работ и добиться необходимых результатов с наименьшими затратами. Применение данной методологии возможно и обоснованно в современных российских условиях. Это касается не только реализации отдельных инновационных проектов в рамках отдельных организаций, но и программ на межрегиональном, государственном и международном уровнях.

Инновационный потенциал предприятия характеризуется его способностью продуцирования новшеств и нововведений собственными силами или приобретения их со стороны, а также эффективного внедрения инноваций в практику хозяйственной деятельности. Результатом реализации инновационного потенциала предприятия является:

- освоение новой и модернизация выпускаемой продукции;

- разработка и внедрение в производство новых машин, оборудования, инструмента, новых конструкционных материалов;

- разработка и внедрение в производство новых технологий и способов производства продукции;

- усовершенствование и разработка новых методов, средств и правил организации и управления производством.

Повышение обоснованности и результативности территориальной политики требует оценки различий условий инновационной деятельности в регионах России для разработки дифференцированных мер государственного регулирования и поддержки применительно к различным типам регионов в зависимости от уровня развития их инновационного потенциала. Сглаживание различий в социально-экономических условиях развития регионов России является главным направлением территориальной политики федерального правительства, для чего анализируют детально ситуацию и выявляют, что именно нуждается в 
выравнивании. Однако часто это сводится только к стремлению максимально сгладить любые различия, что на практике приводит к снижению эффективности производства, торможению научно-технического прогресса, обострению социальной напряженности и другим негативным социально-экономическим последствиям. Поэтому необходимо выравнивание инновационного потенциала территорий, так как основные факторы, определяющие колебания инновационной активности, имеют технологический, отраслевой характер.

Библиографический список:

1. Луков В.А. Российская и мировая практика реализации в обществе инновационного потенциала новых поколений: подходы к исследованию [Текст] // Информационный гуманитарный портал «Знание. Понимание. Умение». - 2012. - № 1.

2. Матвейкин В.Г. Инновационный потенциал: современное состояние и перспективы развития: монография [Текст] / В.Г. Матвейкин, С.И. Дворецкий, Л.В. Минько, В.П. Таров, Л.Н. Чайникова, О.И. Летунова. - М.: «Издательство Машиностроение-1», 2007.

3. Бахтизин А.Р., Акинфеева Е.В. Сравнительные оценки инновационного потенциала регионов РФ // Экономический портал: [Электронный pecypc] URL: http:// institutiones.com/general/1791

4. Петрова Е.В. Формирование сценариев развития экономической системы региона на основе оценки воспроизводственной капитализации компаний: монография / Е. В. Петрова, А. А. Акимочкин, А. С. Молчан. - Краснодар, - 2010.

5. Молчан А.С. Концептуальные аспекты теории и методологии формирования и использования совокупного потенциала мезоуровневых социально-экономических систем // Научный вестник Южного института менеджмента. - 2013. - № 3. - С. 22-28.

6. Молчан А.С. Ретроспективный анализ тенденций развития экономического потенциала региональной социально-экономической системы (на примере Краснодарского края) // Экономические науки. - 2011. - № 76. - С. 46-51. 
В журнал «Экономика и предпринимательство»

\section{Авторская анкета}

\begin{tabular}{|c|c|c|}
\hline \multicolumn{3}{|c|}{ Информация об авторе и публикации } \\
\hline & На русском языке & На английском языке \\
\hline Фамилия & Молчан & Molchan \\
\hline Имя & Алексей & Alexey \\
\hline Отчество & Сергеевич & Sergeevich \\
\hline Ученая степень & Доктор экономических наук & Doctor of Economic Sciences \\
\hline Ученое звание & Доцент & Associated Professor \\
\hline Место работы & $\begin{array}{l}\text { Кубанский государственный } \\
\text { технологический университет }\end{array}$ & Kuban State Technological University \\
\hline Должность & $\begin{array}{l}\text { Профессор кафедры маркетинга и } \\
\text { управления предприятием }\end{array}$ & $\begin{array}{l}\text { Professor of Marketing and Enterprise } \\
\text { Management Department }\end{array}$ \\
\hline & & - \\
\hline & & - \\
\hline & & - \\
\hline & & - \\
\hline & & - \\
\hline Место соискательства & - & - \\
\hline E-mail & molchan.alexey@gmail.com & - \\
\hline Название статьи & $\begin{array}{l}\text { Инновационный потенциал региональной } \\
\text { экономической системы: условия } \\
\text { формирования и факторы развития }\end{array}$ & $\begin{array}{l}\text { Innovative potential of regional } \\
\text { economic system: formation conditions } \\
\text { and factors of development }\end{array}$ \\
\hline Аннотация & $\begin{array}{l}\text { Рассмотрено понятие инновационного } \\
\text { потенциала как экономической категории. } \\
\text { Выделены трактовки к определению } \\
\text { инновационного потенциала } \\
\text { региональной экономической системы. } \\
\text { Определен элементный состав } \\
\text { инновационного потенциала } \\
\text { региональной экономической системы. } \\
\text { Обозначены условия формирования } \\
\text { инновационного потенциала } \\
\text { региональной экономической системы в } \\
\text { контексте стратегических направлений } \\
\text { экономического развития территорий. }\end{array}$ & $\begin{array}{l}\text { The concept of innovative capacity as an } \\
\text { economic category. Highlighted } \\
\text { interpretation to the definition of } \\
\text { innovative potential of regional } \\
\text { economic system. The element } \\
\text { composition of the innovative potential } \\
\text { of the regional economic system. } \\
\text { Designated conditions for the formation } \\
\text { of innovative potential of regional } \\
\text { economic system in the context of the } \\
\text { strategic directions of economic } \\
\text { development of the territories. }\end{array}$ \\
\hline Ключевые слова & $\begin{array}{l}\text { инновационный потенциал, региональное } \\
\text { развитие, инновационная активность, } \\
\text { региональная экономическая система }\end{array}$ & $\begin{array}{l}\text { innovation potential, regional } \\
\text { development, innovation activity, } \\
\text { regional economic system }\end{array}$ \\
\hline
\end{tabular}


В журнал «Экономика и предпринимательство»

Авторская анкета

\begin{tabular}{|c|c|c|}
\hline \multicolumn{3}{|c|}{ Информация об авторе и публикации } \\
\hline & На русском языке & На английском языке \\
\hline Фамилия & Ануфриева & Anufrieva \\
\hline Имя & Анна & Anna \\
\hline Отчество & Петровна & Petrovna \\
\hline Ученая степень & - & - \\
\hline Ученое звание & - & - \\
\hline Место работы & $\begin{array}{l}\text { Российский университет кооперации, } \\
\text { Краснодарский кооперативный институт } \\
\text { (филиал) }\end{array}$ & $\begin{array}{l}\text { Russian University of cooperation, } \\
\text { Krasnodar cooperative Institute (branch) }\end{array}$ \\
\hline Должность & $\begin{array}{l}\text { Ассистент кафедры бухгалтерского учета } \\
\text { и финансов }\end{array}$ & $\begin{array}{l}\text { Assistant of the Department of } \\
\text { Accounting and Finance }\end{array}$ \\
\hline & & - \\
\hline & - & - \\
\hline & & - \\
\hline & & - \\
\hline & & - \\
\hline Место соискательства & - & - \\
\hline E-mail & gubskaya-a@mail.ru & - \\
\hline Название статьи & $\begin{array}{l}\text { Инновационный потенциал региональной } \\
\text { экономической системы: условия } \\
\text { формирования и факторы развития }\end{array}$ & $\begin{array}{l}\text { Innovative potential of regional } \\
\text { economic system: formation conditions } \\
\text { and factors of development }\end{array}$ \\
\hline Аннотация & $\begin{array}{l}\text { Рассмотрено понятие инновационного } \\
\text { потенциала как экономической категории. } \\
\text { Выделены трактовки к определению } \\
\text { инновационного потенциала } \\
\text { региональной экономической системы. } \\
\text { Определен элементный состав } \\
\text { инновационного потенциала } \\
\text { региональной экономической системы. } \\
\text { Обозначены условия формирования } \\
\text { инновационного потенциала } \\
\text { региональной экономической системы в } \\
\text { контексте стратегических направлений } \\
\text { экономического развития территорий. }\end{array}$ & $\begin{array}{l}\text { The concept of innovative capacity as an } \\
\text { economic category. Highlighted } \\
\text { interpretation to the definition of } \\
\text { innovative potential of regional } \\
\text { economic system. The element } \\
\text { composition of the innovative potential } \\
\text { of the regional economic system. } \\
\text { Designated conditions for the formation } \\
\text { of innovative potential of regional } \\
\text { economic system in the context of the } \\
\text { strategic directions of economic } \\
\text { development of the territories. }\end{array}$ \\
\hline Ключевые слова & $\begin{array}{l}\text { инновационный потенциал, региональное } \\
\text { развитие, инновационная активность, } \\
\text { региональная экономическая система }\end{array}$ & $\begin{array}{l}\text { innovation potential, regional } \\
\text { development, innovation activity, } \\
\text { regional economic system }\end{array}$ \\
\hline
\end{tabular}

